Journal of Minerals \& Materials Characterization \& Engineering, Vol. 8, No. 9, pp 693-700, 2009

jmmce.org Printed in the USA. All rights reserved

\title{
Corrosion Behavior of Nanostructured TiAIN and AICrN Hard Coatings on Superfer 800H Superalloy in Simulated Marine Environment
}

\author{
Vikas Chawla $^{\mathrm{a} *}$, D. Puri ${ }^{\mathrm{a}}$, S. Prakash ${ }^{\mathrm{a}}$ and Buta Singh Sidhu ${ }^{\mathrm{b}}$ \\ ${ }^{a}$ Metallurgical \& Materials Engineering Department, I.I.T. Roorkee, Roorkee-247667, India \\ ${ }^{b}$ Mechanical Engineering Department, Y.C.E., Talwandi Saboo-151302,India \\ *Corresponding author: edwalesir@rediff.com, \\ Phone: +91-9417953530, Fax: +91-1332-285243
}

\begin{abstract}
In this work, TiAlN and AlCrN coatings were deposited on Superfer $800 H$ superalloy using Balzer's rapid coating system (RCS) machine (make Oerlikon Balzers, Swiss) under a reactive nitrogen atmosphere. The corrosion resistance of the substrate, TiAlN and AlCrN coated samples in a $5 \mathrm{wt} \% \mathrm{NaCl}$ solution was evaluated and compared by salt fog (spray) test for 24 hrs, 48 hrs and 72 hrs. The samples were monitored and analyzed by using weight loss measurement, XRD and SEM/EDAX techniques. There was no weight loss observed for coated as well as uncoated specimens in all test conditions.
\end{abstract}

Keywords: Salt fog test, Physical vapor deposition, Corrosion, Nanostructured coatings, Pitting

\section{INTRODUCTION}

Superalloys are extensively used in turbine blades of industrial gas turbines and jet engines [1]. Corrosion of iron /steel and superalloys is affected by the environment to which these are exposed [2]. In a wide variety of applications, for example, in aero and thermal power plants, mechanical components especially turbine engines have to operate under severe conditions, such as high load, speed, temperature and hostile chemical environment [3]. Mostly $\mathrm{Cr}$ and $\mathrm{Al}$ are added in $\mathrm{Fe}$ and Ni-based superalloys to enhance the oxidation resistance. When the superalloys were employed in jet engines, the resistance to pitting corrosion was another property, which can also influence the serving life of engines as it rested on seaside [1]. Besides the oxidation resistance of superalloys at high temperature, the resistance to pitting corrosion at normal temperature is another important performance of these materials.

The atmospheric sulfate and chloride pollutants can enhance conductivity of the wet film on the metal surface, leading to the metal deterioration process [2, 4]. Chloride ions present in sea aerosol can be considered as a natural pollutant $[2,4]$. Chloride ions serve as the catalyzer in accelerating the corrosion process. Dobrzanski et al., [5] reported that the chloride-rich seawater 
is a harsh environment that can attack the materials by causing pitting and crevice corrosion. The maximum corrosion rate occurs near $3.5 \% \mathrm{wt} \mathrm{NaCl}$-the approximate salt concentration of seawater. Although numerous studies in the literature reported the high temperature corrosion behavior of bulk alloys and metallic coatings on boiler steels, behavior of corrosion occurring at room temperature in marine environment, is scarce in the literature.

In recent years, corrosion performance of nanostructured materials/coatings is a hot topic in corrosion field. As reported by Chawla et al. [6], in the past decade, attractive properties associated with a nanostructure have been documented for bulk materials, where most of the research in the field of nanomaterials has been focused. Nanostructured materials indeed behave differently than their microscopic counterparts because their characteristic sizes are smaller than the characteristic length scales of physical phenomenon occurring in bulk materials [7].

This work has been focused to compare the corrosion behavior of nanostructured thin (by physical vapor deposition process) TiAlN and AlCrN coatings deposited on Superfer $800 \mathrm{H}$ (INCOLOY $800 \mathrm{H}$ ) substrate, by salt spray (Fog) tests.

\section{EXPERIMENTAL DETAILS}

\subsection{Development of Coatings}

TiAlN and AlCrN coatings; with a thickness around $4 \mu \mathrm{m}$, were deposited on Fe-based Superfer $800 \mathrm{H}$ superalloy, which was procured in the form of rolled sheets from Mishra Dhatu Nigham Ltd, Hyderabad (India).. The selected superalloy is widely used for steam boilers, furnace equipment and piping in the chemical industry, baffle plates/tubes in fertilizer plants. The actual chemical composition of the substrate steel analyzed with the help of Optical Emission Spectrometer of Thermo Jarrel Ash (TJA 181/81), USA make. The actual chemical composition of the Superfer $800 \mathrm{H}$ superalloy has been analyzed with the help of Optical Emission Spectrometer of Thrmo Jarrel Ash (TJA181/81), U.S.A make. Normal and actual chemical composition is reported in Table 1.

Table 1: Chemical composition (wt \%) of Superfer 800H (INCOLOY $800 \mathrm{H}$ )

\begin{tabular}{lcccccccc}
\hline Elements & $\mathrm{C}$ & $\mathrm{Mn}$ & $\mathrm{Si}$ & $\mathrm{Cr}$ & $\mathrm{Ni}$ & $\mathrm{Ti}$ & $\mathrm{Al}$ & $\mathrm{Fe}$ \\
\hline Nominal & 0.10 & 1.0 & 0.6 & 19.5 & 30.8 & 0.44 & 0.34 & $\mathrm{Bal}$. \\
Actual & 0.10 & 1.5 & 1.0 & 21.0 & 32.0 & 0.30 & 0.30 & $\mathrm{Bal}$. \\
\hline
\end{tabular}

Specimens with dimensions of approximately $20 \mathrm{~mm} \times 15 \mathrm{~mm} \times 5 \mathrm{~mm}$ were cut from the alloy sheet. Polished using emery papers of 220, 400, 600 grit sizes and subsequently on 1/0, 2/0, 3/0, and $4 / 0$ grades, and then mirror polished using cloth polishing wheel machine with $1 \mu m$ 
lavigated alumina powder suspension. The specimens were prepared manually and all care was taken to avoid any structural changes in the specimens.

The nanostructured thin TiAlN and AlCrN coatings; with a thickness around $4 \mu \mathrm{m}$, were deposited on the substrates at Oerlikon Balzers Coatings India Limited, Gurgaon, India. A frontloading Balzer's rapid coating system (RCS) machine (make Oerlikon Balzers, Swiss) was used for the deposition of the coatings. The grain size of the thin films was estimated by Scherrer formula from XRD diffractogram and by Atomic force microscopy (AFM; Model: NTEGRA, NT-MDT, Ireland). The grain size for TiAlN and AlCrN coatings was found $09 \mathrm{~nm}$ and $22 \mathrm{~nm}$ respectively. The details of the coating parameters and coating characterization have been reported in another paper (communicated).

\subsection{Salt Spray (Fog) Testing and Analysis of the Corroded Specimens}

The ASTM B117 Salt Fog test was used to evaluate the performance of the uncoated and nanostructured thin TiAlN and AlCrN coatings. The salt fog test is an accelerated corrosion test by which samples exposed to the same conditions can be compared. In the B117 test, the samples are exposed to a salt fog generated from a 5\% sodium chloride solution with a $\mathrm{pH}$ between 6.5 and 7.2 in salt fog testing set up (HSK 1000, Heraeus Votsch, Germini) as shown in Figure 1. The salt solution employed was prepared with $\mathrm{NaCl}$ analytical grade reagent with minimum assay 99.9 \% supplied by Qualigens Fine Chemicals, Mumbai, India and deionised water.

All the samples were placed in the salt fog chamber for $24 \mathrm{Hrs}, 48 \mathrm{Hrs}$ and 72 Hrs. Photographs were taken before and subsequent to exposure to document the surface conditions. Initial weight and dimensions were measured. The uncoated as well as the coated specimens were polished down to $1 \mu \mathrm{m}$ alumina wheel cloth polishing to obtain similar condition on all the samples before salt fog testing.

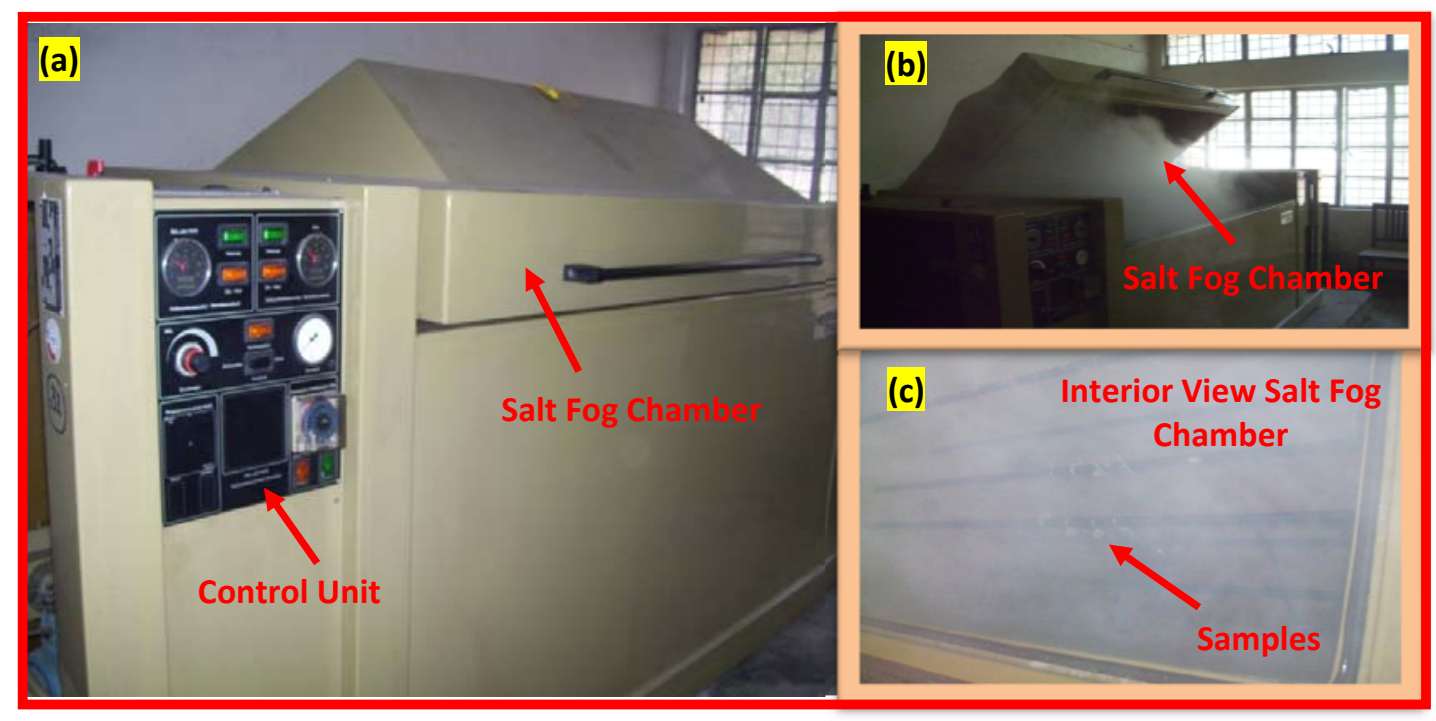

Figure 1. Experimental set-up for Salt spray (Fog) testing (a) Salt fog testing set up, (b) Salt fog chamber, (c) Interior view of chamber 


\subsection{Analysis of the Corroded Specimens}

After exposure; samples were monitored and analyzed by using XRD and SEM/EDAX techniques. Visual examination was made after the completion of the tests and the macrographs of the corroded specimens were taken. Surface SEM analysis of the corroded specimens was conducted using Field emission scanning electron microscope (FEI Company, Quanta 200F) with EDAX attachment. EDAX analysis at few points of interest was taken. XRD analysis was carried out for the as coated specimens to identify the various phases present on their surfaces. The X-ray diffraction patterns were obtained by a Bruker AXS D-8 Advance Diffractometer (Germany) with $\mathrm{CuK}_{\alpha}$ radiation and nickel filter at $30 \mathrm{~mA}$ under a voltage of $40 \mathrm{kV}$. The specimens were scanned with a scanning speed of $2^{\circ} / \mathrm{min}$ in $2 \theta$ range of $20^{\circ}$ to $120^{\circ}$ and the intensities were recorded. Before salt fog testing; the samples were cleaned in acetone, dried, weighed to an accuracy of $1 \times 10^{-5} \mathrm{~g}$ using an electronic balance. After exposure; samples were monitored and analyzed by using XRD and SEM/EDAX techniques. Then all the samples were cleaned in running water not warmer than $38^{\circ} \mathrm{C}$ to remove salt deposits from the surface and then immediately dried with compressed air. The final weight was measured and then the weight loss per unit area was calculated.

\section{RESULTS AND DISCUSSION}

The ASTM B117 Salt Fog test was used to evaluate the performance of the uncoated and nanostructured thin TiAlN and AlCrN coated Superfer $800 \mathrm{H}$ superalloy. The salt fog test is an accelerated corrosion test by which samples exposed to the same conditions can be compared. In the B117 test, the samples are exposed to a salt fog generated from a 5\% sodium chloride solution with a pH between 6.5 and 7.2. All the samples were placed in the salt fog chamber for 24 Hrs, 48 Hrs and 72 Hrs. Photographs were taken before and subsequent to exposure to document the surface conditions. Initial weight and dimensions were measured. After exposure; samples were monitored and analyzed by using XRD and SEM/EDAX techniques. Then all the samples were cleaned in running water not warmer than $38^{\circ} \mathrm{C}$ to remove salt deposits from the surface and then immediately dried with compressed air.

The macro morphologies of the uncoated and nanostructured thin TiAlN and AlCrN coated superalloy exposed to salt fog test for $24 \mathrm{Hrs}, 48 \mathrm{Hrs}$ and $72 \mathrm{Hrs}$; are depicted in Figure 2. No signs of corrosion have been observed in case of uncoated and coated Superfer $800 \mathrm{H}$ superalloy subjected to salt fog tests for different durations. The surface appearance of all the samples remains untouched. Figure 2 shows the surface SEM images of uncoated and nanostructured TiAlN and AlCrN coated superalloy exposed to salt fog test for 72 Hrs. The SEM/EDAX analysis of the samples exposed to $24 \mathrm{Hrs}, 48 \mathrm{Hrs}$ and $72 \mathrm{Hrs}$ salt fog tests have shown similar results i.e. no corrosion products have been found on the surface. So, the SEM/EDAX analysis in case of salt for tests for 72 Hrs (maximum duration in present test) has been presented here. 


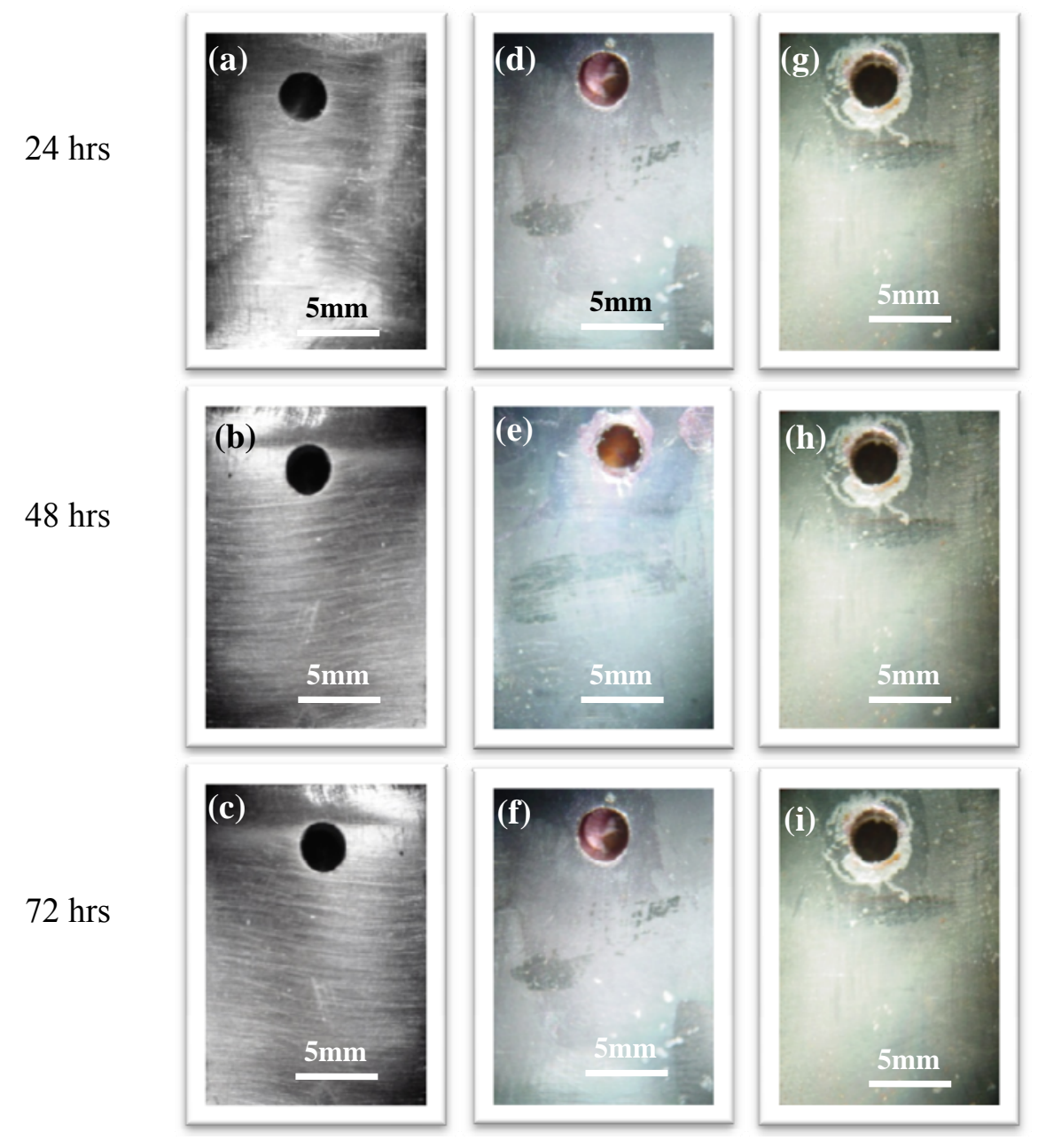

Figure 2. Surface macrographs of uncoated and coated Superfer $800 \mathrm{H}$ superalloy subjected to salt-fog testing $(5 \% \mathrm{NaCl}):(\mathrm{a}),(\mathrm{b})$ and (c) Uncoated Superfer $800 \mathrm{H}$ subjected to 24hrs, 48hrs and $72 \mathrm{hrs}$ testing, respectively; (d), (e) and (f) Nanostructured TiAlN coating subjected to $24 \mathrm{hrs}$, $48 \mathrm{hrs}$ and $72 \mathrm{hrs}$ testing, respectively; (g), (h) and (i) Nanostructured $\mathrm{AlCrN}$ coating subjected to $24 \mathrm{hrs}$, 48hrs and $72 \mathrm{hrs}$ testing, respectively

As can be seen in Figure 3; no corrosion product has been found on the surface of any sample. The EDAX point analysis at some points of interest points out the presence of $\mathrm{Fe}, \mathrm{Ni}$ and $\mathrm{Cr}$ in case of uncoated superalloy (Point 1 and 2 in Figure 3). In case of nanostructured thin TiAIN and AlCrN coatings; no corrosion products were seen (Figure 3. b \& c). The EDAX point analysis (Point 3 to 6 in Figure 3) revealed the presence of the coating elements only. So, in case of 72 Hrs test conditions; the uncoated and nanostructured thin coatings have performed well in salt fog tests.

XRD diffractograms for coated and uncoated Superfer $800 \mathrm{H}$ superalloy subjected to salt fog tests for $24 \mathrm{Hrs}, 48 \mathrm{Hrs}$ and $72 \mathrm{Hr}$; are depicted in Figure 4 on reduced scale. As indicated by the diffractograms in Figure 4: $\mathrm{Fe}, \mathrm{Ni}$ and $\mathrm{Cr}$ are the main phases present in case of uncoated 
superalloy. In nanostructured TiAlN coating, AlN and TiN are the main phases revealed by EDAX analysis. Further, the main phases identified for the nanostructured AlCrN coating are CrN and AlN.
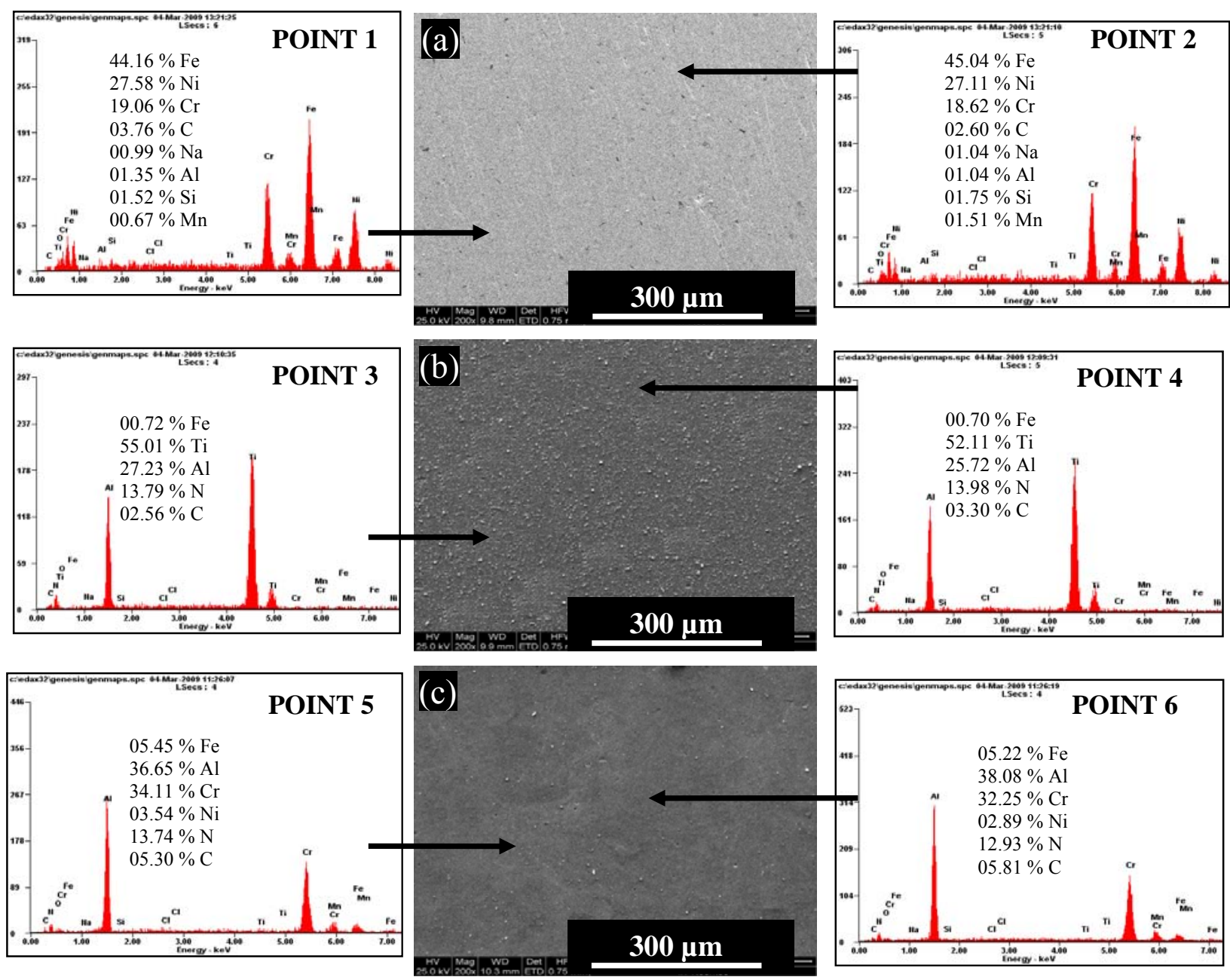

Figure 3. Surface macrographs of uncoated and coated Superfer $800 \mathrm{H}$ superalloy subjected to salt-fog testing $(5 \% \mathrm{NaCl})$ for $72 \mathrm{hrs:} \mathrm{(a)} \mathrm{Uncoated} \mathrm{Superfer} 800 \mathrm{H}$ superalloy (b) Nanostructured TiAlN coating (c) Nanostructured AlCrN coating.

The weight loss measurements were carried out for the uncoated and nanaostructured thin TiAlN and $\mathrm{AlCrN}$ coated Superfer $800 \mathrm{H}$ supealloy exposed to the salt fog tests for $24 \mathrm{Hrs}, 48 \mathrm{Hrs}$ and 72 Hrs. No weight change was observed in any case. It can be mentioned based on the present investigation that uncoated Superfer $800 \mathrm{H}$ and nanostructured thin TiAlN and AlCrN coatings can provide a very good corrosion resistance when exposed to the simulated marine environment i.e. salt fog test. 


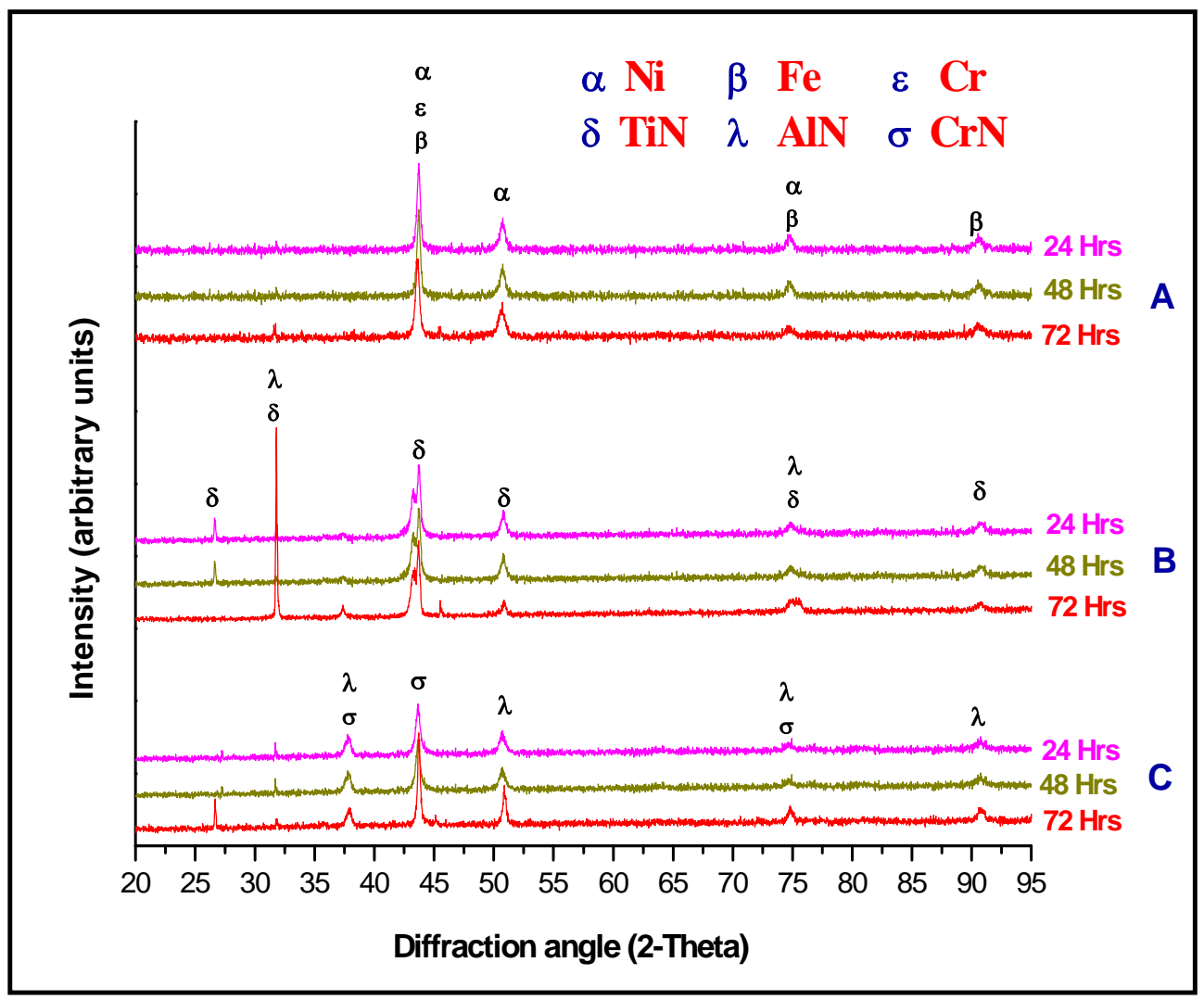

Figure 4. X-Ray Diffraction pattern of uncoated and coated Superfer $800 \mathrm{H}$ superalloy subjected to salt-fog testing $(5 \% \mathrm{NaCl})$ : (A) Uncoated Superfer $800 \mathrm{H}$ superalloy, (B) Nanostructured TiAlN coating, (C) Nanostructured AlCrN coating.

\section{CONCLUSIONS}

The corrosion behavior of the nanostructured thin (by physical vapor deposition process) TiAlN and AlCrN coatings on Superfer $800 \mathrm{H}$ superalloy; has been analyzed by salt spray (Fog) tests $(5.0 \mathrm{wt} \% \mathrm{NaCl})$. The following conclusions can be made:

1. In salt spray tests; the uncoated as well as nanostructured TiAlN and AlCrN coated Superfer $800 \mathrm{H}$ superalloy have performed very well. The uncoated as well as coated samples have shown no weight change during exposure for $24 \mathrm{Hrs}, 48 \mathrm{Hrs}$ and $72 \mathrm{Hrs}$ to salt fog tests and fully protected the substrate material.

2. It can be mentioned based on the present investigation that uncoated Superfer $800 \mathrm{H}$ and nanostructured thin TiAlN and AlCrN coatings have shown a very good corrosion resistance when exposed to the simulated marine environment i.e. salt fog test. 


\section{ACKNOWLEDGEMENT}

The authors wish to thank All India Council for Technical Education (A.I.C.T.E.), New Delhi, India for providing National Doctoral Fellowship (NDF) to Mr. Vikas Chawla (corresponding author) and grant under Nationally Coordinated Project (NCP).

\section{REFERENCES}

[1] Li Liu, Ying Li and Fuhui Wang; Electrochimica Acta; 2007; 52; 2392-2400.

[2] Gadadhar Sahoo and R. Balasubramaniam; Journal of ASTM International;2008; Vol.5, No. 5, Paper ID JaI101191.

[3] R.A. Mahesh, R. Jayaganthan, S. Prakash; J Alloys and Compounds; 2009; 468 ; 392-405.

[4] Corvo, F., Betancourt, N., and Mendoza, A.; Corrosion Science; 1995; 37; 1889-1901.

[5] L. A. Dobrzanski, Z. Brytan, M. Actis Grande, M. Rosso; Journal of Materials Processing Technology; 2007; 192-193; 443-448.

[6] Vikas Chawla, Buta Singh Sidhu, D. Puri and S. Prakash, J of the Australian ceramic society; 2008; 42; 56-62.

[7] Vikas Chawla, S. Prakash and B.S. Sidhu; Materials and Manufacturing Processes; 2007; 22 ; 469-473. 